Hospital, Rheumatology, Bilbao, Spain; ${ }^{2}$ Basurto University Hospital, Investigation, Bilbao, Spain

Background: In our population the prevalence of hypovitaminosis D is high. A recent cross-sectional observational study conducted in Spain shows that $63 \%$ of postmenopausal women who receive osteoporosis (OP) therapy and $76 \%$ who do not receive treatment had $25(\mathrm{OH}) \mathrm{D}$ levels below $30 \mathrm{ng} / \mathrm{mL}$.

The latest studies show a relationship between hypovitaminosis $\mathrm{D}$ and the development of systemic inflammatory and tumor diseases, determined by the presence of receptors in various tissues, including breast.

Objectives: To determine which levels of serum $25(\mathrm{OH}) \mathrm{D}$, and secondarily calcium, phosphorus, PTH and CTX, present 200 patients diagnosed with breast cancer and taking hormonal treatment, referred to a monographic OP consultation of a tertiary hospital for the assessment of their bone metabolism, and if these values differ from what is expected for the general population.

Methods: Retrospective cross-sectional study of 200 women diagnosed with breast cancer receiving treatment with aromatase inhibitors (Al), performed in a tertiary hospital. Blood levels of vitamin D, calcium, phosphorus, PTH and CTX have been collected, as well as other variables and risk factors.

Results: 200 patients with a mean age of 64.8 years and an ED of 9.5 were collected. The median is 64.5 (Q1 58 and Q3 72).

The vitamin $D$ levels presented by the study patients were $<10 \mathrm{ng} / \mathrm{mL}$ in 13 patients $(6.67 \%), 11-20 \mathrm{ng} / \mathrm{mL}$ in $50(25.64 \%), 21-30 \mathrm{ng} / \mathrm{mL}$ in $68(34.87 \%)$, $31-70 \mathrm{ng} / \mathrm{mL}$ in $62(31.79 \%)$, and $>70 \mathrm{ng} / \mathrm{mL}$ in $2(1.03 \%)$. This implies that in $67.18 \%$ of the patients they had values below the optimal range.

$92.31 \%$ of patients (180) presented PTH values within the normal range and only $7.69 \%$ presented values above normal.

The serum calcium and phosphorus levels of the patients selected for the study had ranges within normal $(99.49 \%)$ except 1 case that presented high values $(0.51 \%)$ for both.

The values of CTX (carboxyterminal telopeptide used as a marker of bone resorption) were in the normal range in $81.96 \%$ of patients (159), low values in $0.52 \%$ (1) and values above the normal range by $17.53 \%$ (34).

Conclusion: The prevalence of insufficient levels of vitamin D in our study (Breast cancer $+\mathrm{Al}$ ) is not greater than that estimated for the general population according to various studies.

Our study found that $67.18 \%$ of patients (2/3 of the selected population) had values below those considered optimal ( $<30 \mathrm{ng} / \mathrm{mL}$ ) and $32 \%$ had values $<20$. Only $7.69 \%$ of the patients presented PTH values above the normal range.

In $82 \%$ of patients, CTX used as a marker of bone resorption had normal values. References:

[1] Quesada Gomez JM, Díaz Curiel M, Sosa Henríquez M, Malouf-Sierra J, Nogués-Solan X, Gómez-Alonso C, et al. Low calcium intake and insufficient serum vitamin D status in treated and non-treated postmenopausal osteoporotic women in Spain. J Steroid Biochem Mol Biol. 2013;136:175-7.

[2] Jian Sun et al., Vitamin D receptor expression in peripheral blood mononuclear cells is inversely associated with disease activity and inflammation in lupus patients; Clinical Rheumatology (2019) 38:2509-2518

Disclosure of Interests: None declared

DOI: 10.1136/annrheumdis-2020-eular.5595

\section{AB0907 BONE METABOLISM ASSESSMENT IN PATIENTS WITH RECENT DIAGNOSIS OF GIANT CELL ARTERITIS}

A. Nack ${ }^{1}$, I. Casafont-Solé ${ }^{1}$, L. Mateo ${ }^{1}$, S. Holgado Pérez ${ }^{1}$, M. Martínez-Morillo, M. Aparicio Espinar ${ }^{1}$, A. Riveros ${ }^{1}$, C. Sanguesa ${ }^{1}$, Á. Prior-Español ${ }^{1}$, M. Aparicio Rovira ${ }^{1}$, A. Olive ${ }^{1}$, L. Gifre ${ }^{1} .{ }^{1}$ Hospital Germans Trias i Pujol, Badalona, Spain

Background: There are several studies assessing bone mass and osteoporosis (OP) development of patients with giant cell arteritis (GCA) during glucocorticoid treatment, however data at time of diagnosis is scarce.

Objectives: To analyze bone metabolism, bone mineral density (BMD) and trabecular microarchitecture by measuring trabecular bone score (TBS) in patients with recent diagnosis of GCA.

Methods: Retrospective observational study in which we included all patients with GCA and bone metabolism assessment at diagnosis. We recorded: risk factors for OP (previous fractures and anti-OP treatments), bone metabolism (calcium, phosphate, PTH, 25-vitaminD [25-OHD]) and the DXA results (Lunar, DPX) at the time of diagnosis and during the follow-up. The statistic analysis was made with SPSS.

Results: 36 patients ( $27 \mathrm{~W}$ : $9 \mathrm{M}$ ) with a mean age of $76 \pm 9$ years were included. The clinical characteristics of the GCA at diagnoses were: headache (81\%), constitutional syndrome $(58 \%)$, allodynia $(42 \%)$, visual loss $(42 \%$, binocular in 2 patients), jaw claudication (39\%), polymyalgic syndrome (28\%), amaurosis fugax $(25 \%)$ and lingular necrosis $(n=1,3 \%)$. Additional diagnosis tests included: temporal biopsy ( $86 \%$, being pathologic in $55 \%)$, temporal ultrasound $(97 \%$, pathologic $34 \%$ ), extra-cranial arteries ultrasound ( $81 \%$, pathologic $7 \%$ ) and PET/CT (19\%, pathologic $86 \%)$. Up to $61 \%$ received three metilprednisolone bolus (mean dose $1700 \mathrm{mg}$ ). 7 patients (19\%) had previous OP and 3 had already suffered a fragility fracture (Colles, vertebral and femur). Only 4 patients were receiving anti-OP treatment ( 2 oral bisphosphonate, 2 zoledronate).

At time of diagnosis of GCA, the mean of $250 \mathrm{HD}$ was $17 \pm 13 \mathrm{ng} / \mathrm{mL}(88 \%,<30)$. BMD showed low bone mass in $80 \%$ of patients ( $47 \%$ with OP, $33 \%$ osteopenia). The mean TBS was $1.026 \pm 0.098$ and up to $38 \%$ showed poor bone microar chitecture [values <1.23]). No significant differences were observed between patients with or without TBS $<1.23$. Up to $94 \%$ of patients received anti-OP treatment (26 zoledronate, 6 oral bisphosphonate, 1 denosumab, 1 teriparatide). 3 patients had incidental fractures during the follow-up, however no relation was found with BMD or TBS.

Conclusion: Low bone mass and vitamin $\mathrm{D}$ insufficiency are frequent in patients with recent diagnoses of GCA and up to $38 \%$ have poor bone microarchitecture at baseline. Thus, it's important to perform a bone mass assessment in all patients with recent diagnose of $A C G$ and initiate therapeutic or preventive anti-OP treatment if required.

Disclosure of Interests: None declared

DOI: 10.1136/annrheumdis-2020-eular.3047

\section{AB0908 $\quad$ ASSESSMENT OF THE IMPACT OF THE LEAN MASS WITH BODY COMPOSITION BY DUAL-ENERGY X-RAY ABSORPTIOMETRY ON THE BONE MINERAL DENSITY}

\section{Nikolov ${ }^{1}$, N. Nikolov ${ }^{1}{ }^{1}$ UMBAL Dr Georgi Stranski, Pleven, Bulgaria}

Background: Lean mass, mainly composed of muscle, has been correlated to bone mineral density (BMD) [4]. Studies reported that lean mass has an important impact on BMD not only in young women but also in postmenopausal women [1] High lean mass is more favorable for the BMD than low lean mass. Some studies suggested that genetic factors responsible for both lean mass and BMD are shared [3]. Low muscle mass and low BMD could impair the quality of the patient's life [2, 5]. Objectives: The aim of this study is to assess the impact of the lean mass with body composition by dual-energy $\mathrm{X}$-ray absorptiometry on the bone mineral density. Methods: 107 women underwent body composition analysis by dual-energy X-ray absorptiometry (DXA). Lean mass in $\mathrm{kg}$ and BMD in $\mathrm{kg} / \mathrm{cm} 2$ were analyzed. Nor mal BMD was defined as T-score $>-1.0$ standard deviation (SD). Osteopenia was defined as T-score between -1.0 SDs and -2.5 SDs and osteoporosis was defined as T-score $\leq-2.5$ SDs.

Results: The mean age of the women was 57 years (yrs.) \pm 11 yrs. (range $41 \mathrm{yrs}$. $-80 \mathrm{yrs}$.). Subjects had mean weight of $75 \mathrm{~kg} \pm 12 \mathrm{~kg}$ (range $50 \mathrm{~kg}-110 \mathrm{~kg}$ ) and mean height of $156 \mathrm{~cm} \pm 9 \mathrm{~cm}$ (range $151 \mathrm{~cm}-172 \mathrm{~cm}$ ). 73/107 women $(68.2 \%)$ were with normal BMD, 24/107 women (22.4\%) were with osteopenia and 10/107 women $(9.4 \%)$ were with osteoporosis. Lean mass differed significantly between the groups $(p=0.000)$. Women with normal BMD had the highest mean lean mass $(58.47 \mathrm{~kg})$ and the mean lean mass of the women with osteopenia and osteoporosis decreased as follow: $47.56 \mathrm{~kg}$ for women with osteopenia and $36.22 \mathrm{~kg}$ for women with osteoporosis.

Conclusion: Women with osteoporosis have the lowest lean mass compared to the women with osteopenia and osteoporosis.

References:

[1] Ilesanmi-Oyelere BL, Coad J, Roy N, Kruger MC. Lean Body Mass in the Prediction of Bone Mineral Density in Postmenopausal Women. Biores Open Access. 2018;7(1):150-158. Published 2018 Oct 10. doi:10.1089/ biores.2018.0025.

[2] Kirilov N., Vladeva SG, Kirilova E. Assessment on the Improvement of the Quality of Life after One Year of Regular Physical Activity and Treatment in Patients with Postmenopausal OsteoporosisCOR 2017: 19th International Conference on Orthopedics and Rheumatology Miami, USA March 9 - 10, 2017, WASET, Paper Code 17US030051.

[3] Nguyen TV, Howard GM, Kelly PJ, Eisman JA. Bone mass, lean mass, and fat mass: same genes or same environments? Am J Epidemiol. 1998 Jan 1;147(1):3-16.

[4] Patel HP, Dawson A, Westbury LD, et al. Muscle Mass, Muscle Morphology and Bone Health Among Community-Dwelling Older Men: Findings from the Hertfordshire Sarcopenia Study (HSS). Calcif Tissue Int. 2018;103(1):35-43. doi:10.1007/s00223-018-0388-2.

[5] Kirilova E, Kirilov N, Vladeva S. A study on the physical activity in women with decreased bone mineral density. Abstract book $13^{\text {th }}$ science conference MC, Pleven

Disclosure of Interests: None declared

DOI: 10.1136/annrheumdis-2020-eular.4525

\section{AB0909 \\ TREATMENT WITH DENOSUMAB IN GLUCOCORTICOSTEROID-INDUCED OSTEOPOROSIS IN PATIENTS WITH RHEUMATOID ARTHRITIS}

M. Osipyan ${ }^{1}$, M. Efraimidou², S. Bazeyan ${ }^{2}$, A. Antikyan², V. Vardanyan², K. Ginosyan ${ }^{1} .{ }^{1}$ Yerevan State Medical University, Rheumatology, Yerevan, Armenia; ${ }^{2}$ Yerevan State Medical University, Yerevan, Armenia 